\title{
Histochemistry of the surface mucous gel layer of the human colon
}

\author{
K Matsuo, H Ota, T Akamatsu, A Sugiyama, T Katsuyama
}

Department of Second Internal Medicine and Laboratory Medicine, Shinshu University School of Medicine, 3-1-1 Asahi, Matsumoto 390, Japan K Matsuo

\section{Department of} Laboratory Medicine, Shinshu University School of Medicine, 3-1-1 Asahi, Matsumoto 390, Japan H Ota

T Katsuyama

Department of Endoscopy, Shinshu University Hospital, 3-1-1 Asahi, Matsumoto 390, Japan T Akamatsu

First Department of Surgery, Shinshu University School of

Medicine, 3-1-1 Asahi, Matsumoto 390, Japan A Sugiyama

Correspondence to:

Dr Tsutomu Katsuyama, Department of Laboratory Medicine,

Medicine, University School of

Medicine,

Matsumoto 390, Japan

Accepted for publication 23 January 1997

\begin{abstract}
Background and aims-Histochemical analysis of the surface mucous gel layer of the human colon is difficult, as it dissolves in fixatives. This study was undertaken to explore the surface mucous gel layer on the normal mucosa and neoplastic tissues of the large intestine. In addition, the distribution of different mucins secreted from goblet cells was studied with a series of histochemical stains for mucins.

Methods-Twenty four surgically resected specimens were fixed in Carnoy's solution and embedded in paraffin. In four cases, the surface mucous gel layer was also studied in frozen sections. Serial sections were stained by a battery of histochemical techniques characterising mucins.

Results and conclusion-The surface mucous gel layer consisted of the inner and outer layers. The first covered the luminal surface of the mucosa, consisted of mucins, and showed a vertical striped pattern. The second overlaid the first, showed a lateral striped pattern, and was contaminated with bacteria and other substances. Their thickness in paraffin sections varied considerably among the sites in the large intestine, but was the thickest in the rectum and measured 12.7 (SEM 6.0) $\mu \mathrm{m}$ and 88.8 (SEM 80.1) $\mu \mathrm{m}$ respectively. Mucins forming the inner layer were obviously derived from goblet cells underlying it.

(Gut 1997; 40: 782-789)
\end{abstract}

Keywords: surface mucous gel layer, mucin, histochemistry, colon cancer, colon adenoma.

The surface mucous gel layer of the large intestine probably serves as a lubricant to protect the mucosa. Its study in ordinary microscopical preparations is hampered by its loss during fixation. Stabilisation of the surface mucous gel layer was attained by Ota and Katsuyama by fixing surgically removed stomach in cooled Carnoy's solution, clearing in xylene, embedding in paraffin wax, and sectioning. ${ }^{1}$ The surface mucous gel layer was well preserved. Some of us applied this technique to study the surface mucous gel layer of the large intestine and showed that it consisted of two layers, an inner obliquely striped layer and an outer multilaminated layer. ${ }^{2}$ The present study was undertaken to elucidate the distribution of the surface mucous gel layer on normal mucosa and neoplastic tissues of the large intestine. In addition, the distribution of different mucins secreted from goblet cells was studied by using a series of histochemical stains for mucins.

\section{Materials and methods}

Twenty four samples of surgically removed human colon were used in this study. These materials were obtained from 22 cases of colon cancer, one case of adenoma, and one case of familial adenomatosis coli. Locations of these specimens were caecum (one), ascending colon (three), transverse colon (four), sigmoid colon (eight), and rectum (eight). Immediately after resection all materials were opened along the contralateral portion to the lesion. Without rinsing, the specimens were laid flat with the mucosal surface up and pinned on cardboard. In 13 cases, $3 \%$ alcian blue solution in distilled water was sprayed onto the mucosal surface before immersing in fixative to investigate whether the mucous gel layer was an artifact during fixation. All specimens were immersed in Carnoy's solution (ethanol 6:acetic acid 3:chloroform $1, v / v / v$ ) for two hours at $4^{\circ} \mathrm{C}$. They were then placed in $100 \%$ alcohol. Materials were sliced longitudinally at regular intervals of $5 \mathrm{~mm}$ width, cleared in xylene, and embedded in paraffin. After histopathological examination, several blocks, which were obtained from the cut end of the materials or included non-neoplastic mucosa as well as neoplastic tissues, were selected for histochemical staining. Serial paraffin sections of $3 \mu \mathrm{m}$ thickness were prepared and stained to analyse mucins in the surface mucous gel layer. The Table gives the histochemical stains used and their histochemical relevance. Alkaline hydrolysis $(1 \%$ potassium hydroxide for 15 minutes at room temperature) was performed to remove $\mathrm{O}$-acetylated groups of 8-O-acetylated $\mathrm{N}$-acetylneuraminic acid (8O-AcNeuAc).

In addition, the surface mucous gel layer was explored in frozen sections in four samples, including two of ascending colon, one of transverse colon, and one of rectum. These materials were removed because of colon cancer, and tissue sections were obtained from macroscopically normal portions. Immediately after removal, these sections were laid in plastic cases (Cryomold, Miles Laboratories, Naperville, IL, USA) and snap frozen in OCT embedding medium (Miles Laboratories, Naperville, IL, USA) by submersion in liquid nitrogen. Sections of $5 \mu \mathrm{m}$ thickness were cut on a cryostat and mounted on poly-L-lysine coated slides (Muto Pure Chemicals, Tokyo, Japan), dried at room temperature, coated with 
Histochemical staining: relevance and sources of reagents

\begin{tabular}{|c|c|c|}
\hline Method & Histochemical relevance & Sources of reagents \\
\hline Alcian blue pH 2.5-PAS (AB/PAS) & To identify acid and neutral mucins. & $\begin{array}{l}\text { Alcian blue (Chroma, Koengen, Germany); basic } \\
\text { fuchsin (Wako Pure Chemical, Osaka, Japan) }\end{array}$ \\
\hline $\begin{array}{l}\text { High iron diamine/alcian blue } \\
\text { pH } 2 \cdot 5(\mathrm{HID} / \mathrm{AB})^{24}\end{array}$ & $\begin{array}{l}\text { To differentiate sulphated mucins } \\
\text { from non-sulphated sialomucins }\end{array}$ & $\begin{array}{l}\text { N,N-dimethyl-m-phenylenediamine } \\
\text { dihydrochloride (Kanto Chemicals, Tokyo, } \\
\text { Japan); N,N-dimethyl-p-phenylenediamine } \\
\text { monohydrochloride (Sigma, St Louis, MO, } \\
\text { USA) }\end{array}$ \\
\hline $\begin{array}{l}\text { Periodic acid/sodium } \\
\text { borohydride/potassium } \\
\text { hydroxide-PAS (PASB/KOH/ } \\
\text { PAS) }\end{array}$ & $\begin{array}{l}\text { To identify sialic acid with an } \\
\text { O-acylated side chain (8-O- } \\
\text { acetyl-N-acetylneuraminic acid or } \\
8-\mathrm{O}-\mathrm{AcNeuAc} \text { ). Such a sialic acid } \\
\text { is most abundant in goblet cells of } \\
\text { the large intestine }\end{array}$ & $\begin{array}{l}\text { Periodic acid (Wako Pure Chemical, Osaka, } \\
\text { Japan); sodium borohydride (Wako Pure } \\
\text { Chemical, Osaka, Japan); potassium hydroxide } \\
\text { (Wako Pure Chemical, Osaka, Japan) }\end{array}$ \\
\hline $\begin{array}{l}\text { Periodic acid-cold thionin } \\
\text { Schiff-potassium hydroxide-PAS } \\
\text { (PA/TS/KOH/PAS) } \text { ) }^{27} 28\end{array}$ & $\begin{array}{l}\text { To differentiate sialic acid with an } \\
\text { adjacent hydroxyl radical (blue) } \\
\text { from those without adjacent } \\
\text { hydroxyl radicals (8-O-AcNeuAc, } \\
\text { magenta) }\end{array}$ & \\
\hline
\end{tabular}

$0 \cdot 2 \%$ celloidin in $1: 1 \mathrm{v} / \mathrm{v}$ ethanol-diethyl ether, and stained by haematoxylin and eosin ( $\mathrm{H}$ and E), alcian blue/periodic acid Schiff (AB/PAS), high iron diamine/alcian blue (HID/AB), periodic acid/sodium borohydride/potassium hydroxide/periodic acid Schiff (PA/SB/KOH/ PAS), or periodic acid/cold thionine Schiff/ potassium hydroxide/periodic acid Schiff (PA TS/KOH/PAS).

The thickness of the surface mucous gel layer was obtained by measuring at 10 randomly selected points in each section with an ocular scale. The thickness was defined as the distance from the outermost layer of the surface mucous gel to the luminal surface of the surface lining cells. The data are expressed as means (SEM).

\section{Results}

HISTOLOGY OF THE SURFACE MUCOUS GEL LAYER

In $\mathrm{H}$ and $\mathrm{E}$ preparations of ileum, no surface mucous gel layer was seen and only amorphous

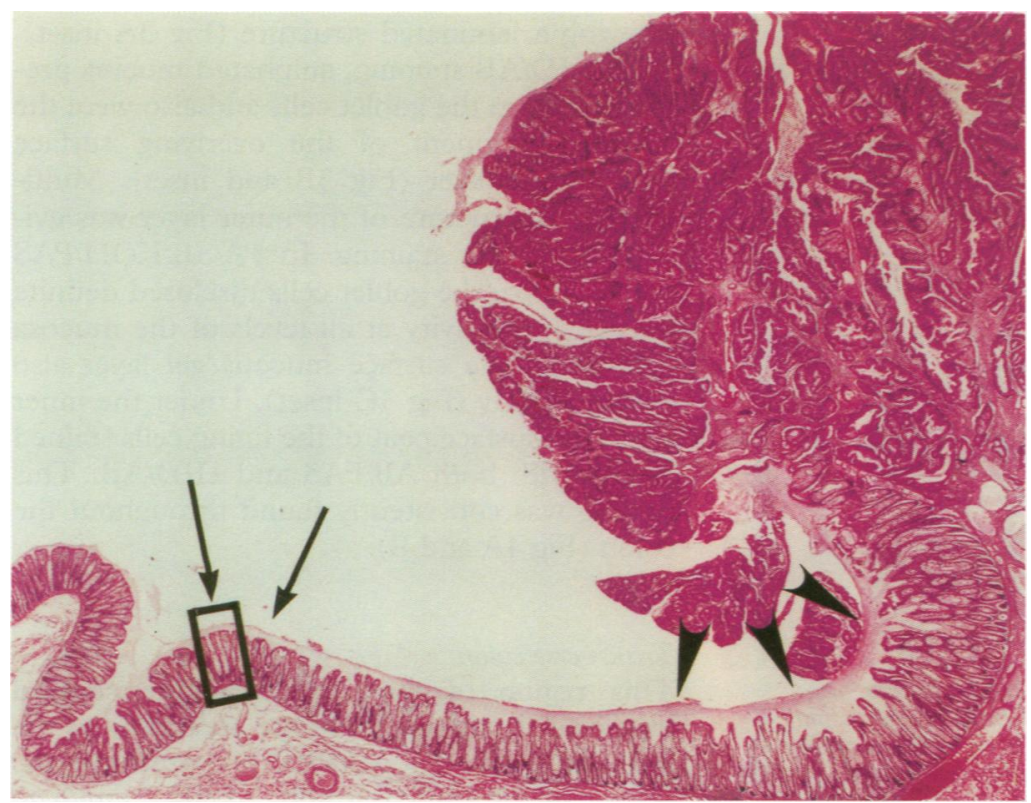

Figure 1: Surface mucous gel layer on normal mucosa, transitional mucosa, and carcinoma. The surface mucous gel layer is thicker on the transitional mucosa (arrow head) than that on the normal mucosa (arrow), but has almost disappeared on carcinoma tissues. $H$ and $E$, originally $\times 9 \cdot 6$. Transverse colon. materials were scattered among villi. In preparations in which alcian blue solution was sprayed on before fixation, the luminal surface of the surface mucous gel layer was continuously covered by this pigment.

The surface mucous gel layer seemed to be a continuous eosinophilic layer coating the mucosal surface (Fig 1 (also Fig 5A)), although its thickness differed considerably among different sites in the large intestine. This layer was differentiated into an inner layer and an outer layer (Fig 2 and inset). The inner layer was consistently attached to the apical surface of the covering epithelia facing the intestinal lumen and was continuous with the intracrypt mucus. An obliquely striped pattern was often evident (Fig 2 and inset), except in the caecum, where this layer appeared as a homogeneous thin band. The outer layer overlaid the inner

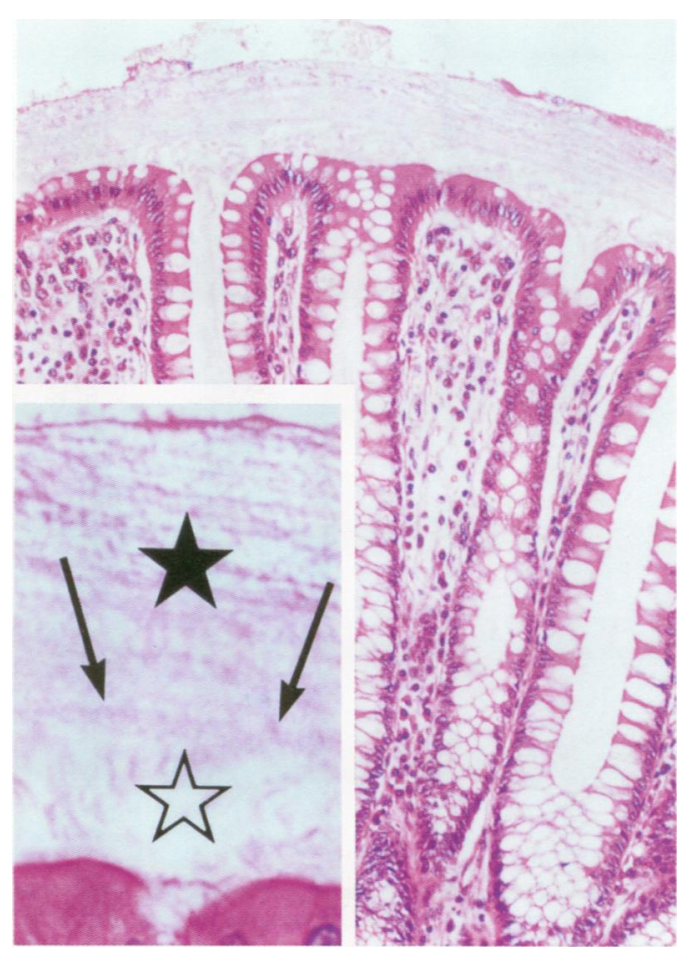

Figure 2: Normal mucosa. Higher magnification of the square shown in Fig 1 . $H$ and $E$, originally $\times 126$. Inset: Higher magnification of Fig 2 . The surface mucous gel layer consists of two layers, the inner layer (open star) and the outer layer (closed star). The arrow indicates the boundery layer. Originally $\times 613$. 
one, was less eosinophilic than the inner layer, and mostly showed a lateral striped pattern (Fig 2 and inset). The surface gel layer was thickest in the rectum and thinnest in the caecum and measured $31 \cdot 1(7 \cdot 2) \mu \mathrm{m}$ (range $26 \cdot 0-36 \cdot 3 \mu \mathrm{m})$ in the caecum, $34.4(8.9) \mu \mathrm{m}$ (range $26 \cdot 8-44 \cdot 1 \mu \mathrm{m}$ ) in the ascending colon, $50.5(14.0) \mu \mathrm{m}$ (range $38.3-4.5 \mu \mathrm{m}$ ) in the transverse colon, $62.0 \quad(31.9) \mu \mathrm{m}$ (range $17 \cdot 3-115 \mu \mathrm{m})$ in the sigmoid colon, and $88 \cdot 8$ $(80 \cdot 1) \mu \mathrm{m}$ (range $46 \cdot 8-284.5 \mu \mathrm{m}$ ) in the rectum. Except in the ascending colon, the inner layer was also thicker in the distal colon and measured approximately $5.6(0.2) \mu \mathrm{m}$ in the caecum, $4.7(1.4) \mu \mathrm{m}$ in the ascending colon, $7.0(3.7) \mu \mathrm{m}$ in the transverse colon, $7.6(3.4) \mu \mathrm{m}$ in the sigmoid colon, and 12.7 $(6 \cdot 0) \mu \mathrm{m}$ in the rectum. Cellular debris, food residues, and bacilli were often seen sandwiched between laminated arrays of the outer layer. The surface mucous gel layer was thicker on the transitional mucosa but had almost disappeared on the adenoma and carcinoma tissues (Fig 1), as described below.

\section{HISTOCHEMISTRY}

\section{Caecum}

In AB/PAS preparations, the goblet cells and intracryptal mucus stained blue/purple. The inner layer stained intensely. The outer layer, on the other hand, stained magenta with
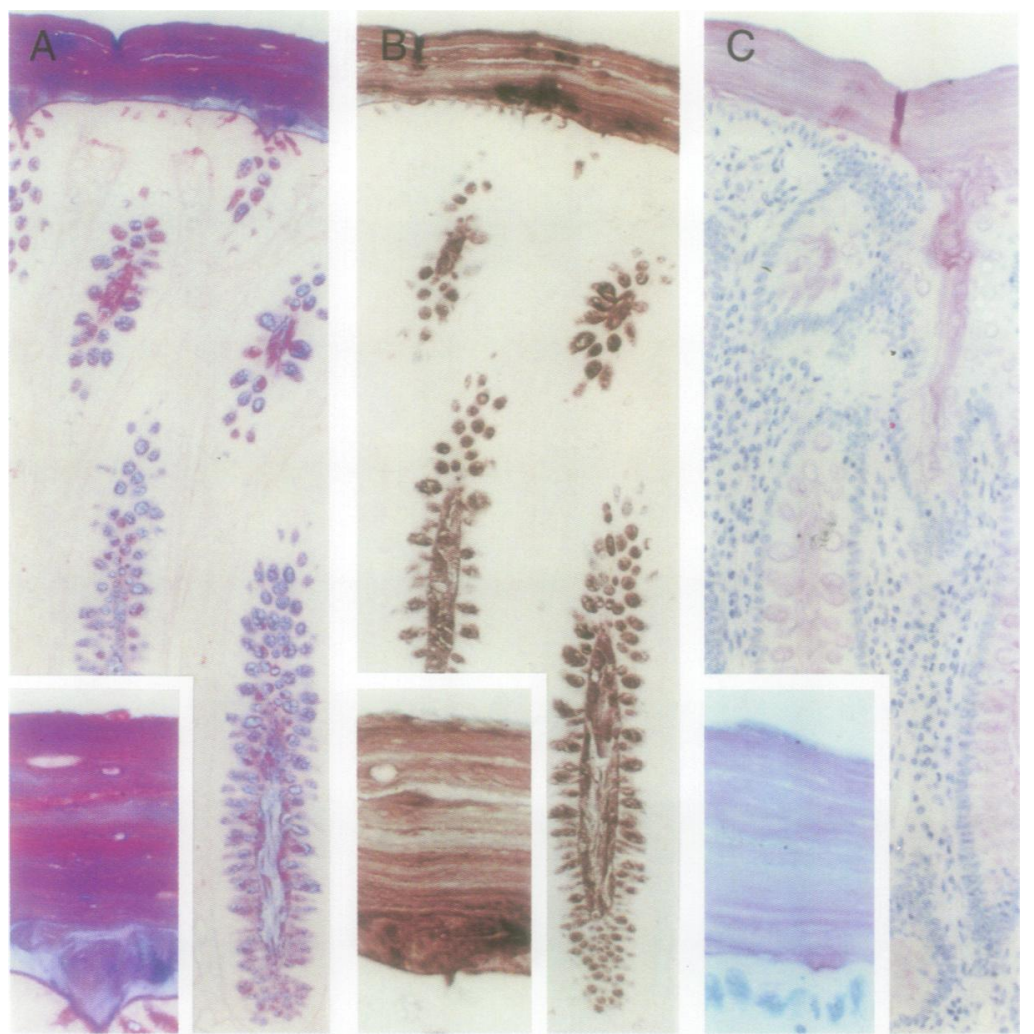

Figure 3: $(A-C)$ Ascending colon prepared from serial sections. Prepared at the same magnification as Fig 5. (A) Originally $\times 26$ and inset $\times 383$. With $A B / P A S$, the inner layer stains irregularly blue, whereas the outer layer stains blue/purple with a stratified arrangement. (B) Sulphated mucins predominate not only in intramucosal mucus but also in the surface mucous gel layer, where the inner layer stains mainly for sulphated mucin, whereas the outer layer shows multilaminated structures. HID/AB stain. (C) The PA/SB/ whereas the outer layer shows multilaminated structures. HID/AB stain. (C) The PA/SB/
$K O H / P A S$ sequence shows weak reactivity, not only in the mucosa but also in the surface mucous gel layer, which shows the multilaminated pattern. PA/SB/KOH/PAS, counterstained with haematoxylin.

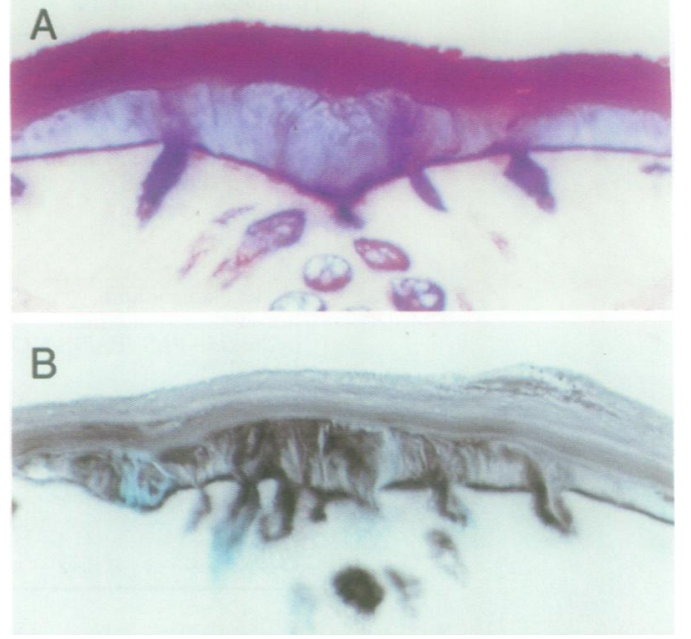

Figure 4: $(A)(A B / P A S)$ and (B) (HID/AB) Higher magnification of the surface mucous gel layer of ascending colon. The surface coat of the surface lining cells persists under the inner layer. Originally $\times 613$.

horizontal stripes of blue/purple. Staining with $\mathrm{HID} / \mathrm{AB}$ showed two layered patterns in each crypt; the goblet cells lining the upper crypt and luminal surface stained predominantly for sulphated mucins, whereas those lining the lower crypt stained for non-sulphated sialomucin. The inner layer of surface mucous gel layer stained black, whereas the outer layer was a greyish blue colour with black horizontal stripes. In preparations stained with $\mathrm{PA} / \mathrm{SB} /$ $\mathrm{KOH} / \mathrm{PAS}$ goblet cells lining the crypts showed almost equal reactivities, as did the intracryptal mucus. The inner layer stained more intensely than the outer layer.

\section{Ascending colon}

With AB/PAS staining, goblet cells and intracryptal mucus predominantly stained blue/ purple throughout the crypts (Fig 3A). The surface mucous gel layer stained blue/purple, showing a laminated structure (Fig 3A inset). With HID/AB staining, sulphated mucins predominated in the goblet cells and also were the major component of the overlying surface mucous gel layer (Fig 3B and inset). Multilaminated structure of the outer layer was evident by mucin staining. In PA/SB/KOH/PAS preparations, the goblet cells disclosed definite but weak reactivity at all levels of the mucosa (Fig 3C). The surface mucous gel layer also stained faintly (Fig 3C inset). Under the inner layer, the surface coat of the lining cells stained clearly with both AB/PAS and HID/AB. This finding was consistently found throughout the colon (Fig 4A and B).

\section{Transverse colon}

This region of the large intestine showed transitional patterns from the ascending to the sigmoid colon. In AB/PAS preparations, the colour of intramucosal goblet cells seemed to show more alcianophilia than that in the ascending colon, especially in the upper and middle portions of the crypts. The inner layer 
of the surface mucous gel layer stained blue/ purple and the outer layer showed a multilaminated structure. In HID/AB preparations, the number of goblet cells containing
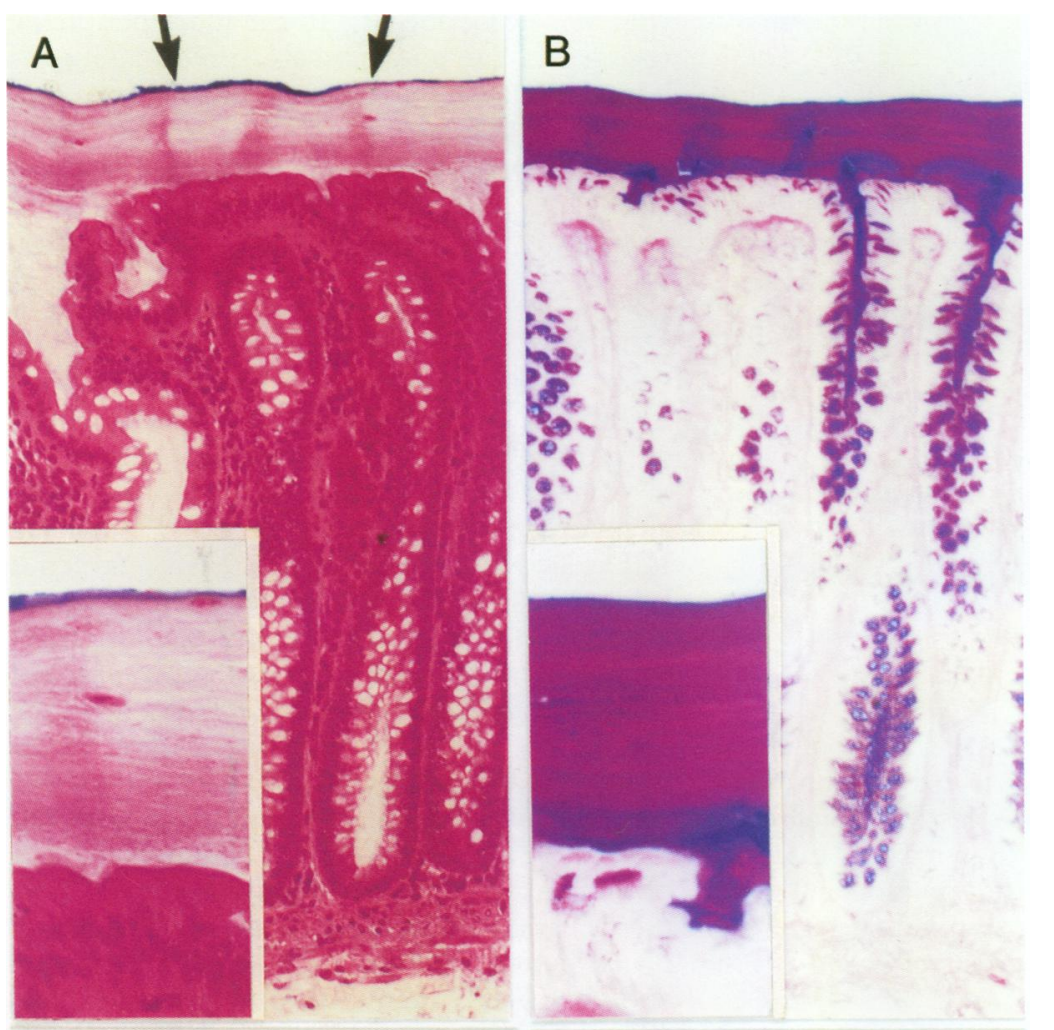

C
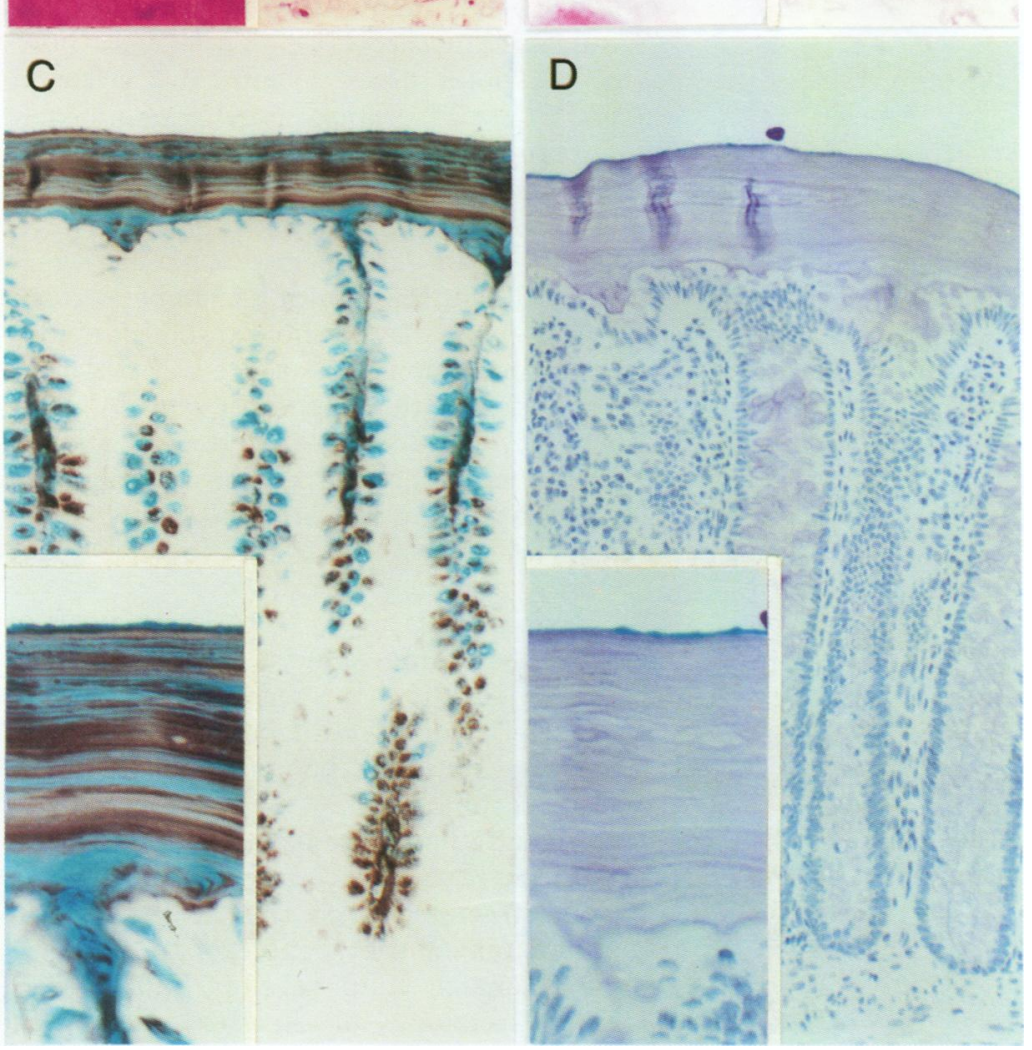

Figure 5: (A-D) Rectum prepared from serial sections. (A) The double layered structure consisting of the inner and outer layers is evident. The luminal surface of the surface mucous gel layer is continuously covered by alcian blue, which was sprayed before fixation (arrows). $H$ and $E$. (B) The inner layer of the surface mucous gel layer stains red/purple but occasionally shows intense alcianophilia, whereas the outer layer shows the multilaminated pattern. AB/PAS. (C) The inner layer of the surface mucous gel layer mostly contains nonsulphated sialomucins, whereas the outer layer shows the multilaminated pattern consisting of non-sulphated sialomucin rich layers and sulphated mucin rich layers. HID/AB. (D) Both the intramucosal mucus and the surface mucous gel layer stain lightly. PA/SB/KOH/ $P A S$, counterstained with haematoxylin. non-sulphated sialomucins slightly increased in the upper portion of the crypts, and nonsulphated sialomucins increased in the inner layer, although those containing sulphated mucins remained predominant. The outer layer also showed a laminated structure in PA/ $\mathrm{SB} / \mathrm{KOH} / \mathrm{PAS}$ preparations, goblet cells lining crypts stained less than those in the ascending colon. The surface mucous gel layer also stained faintly.

\section{Sigmoid colon}

In the preparations stained with AB/PAS, goblet cells stained purple/red. The inner layer stained intensely red, whereas the outer layer stained pale magenta with a lateral striped pattern. In preparations stained with $\mathrm{HID} / \mathrm{AB}$, the number of goblet cells containing sulphated mucins decreased compared with the transverse colon, especially in the upper layer of the mucosa. The inner layer and outer layer stained only faintly, and the outer layer showed multilaminated structures of fine grey stripes on an almost colourless background. In preparations stained with $\mathrm{PA} / \mathrm{SB} / \mathrm{KOH} / \mathrm{PAS}$, both goblet cell mucins and the surface mucous gel layer were stained with moderate intensity. For the surface mucous gel layer, the outer layer almost always exhibited the multilaminated structure consisting of alternating PAS positive and PAS negative layers.

\section{Rectum}

With AB/PAS staining, goblet cells lining crypts and intracryptal mucins stained red/ purple (Fig 5B). The inner layer stained similarly but occasionally showed intense alcianophila. The outer layer, on the other hand, showed alternating laminated structures consisting of blue/purple and blue layers (Fig 5B inset). With HID/AB staining, goblet cells lining the upper crypts predominately stained for non-sulphated sialomucins, whereas those lining the lower crypts stained for sulphated mucins (Fig 5C). The inner layer contained mostly non-sulphated sialomucins, and the outer layer consisted of non-sulphated sialomucins and sulphated mucins abutting each other (Fig 5C inset). With PA/SB/ $\mathrm{KOH} / \mathrm{PAS}$ staining, goblet cells and the surface mucous gel layer stained as lightly as those in the transverse colon (Fig 5D and inset).

\section{Colon adenoma}

Adenomas were recognised in 16 lesions from seven cases. There were two cases of tubulovillous adenoma with moderate dysplasia, eight cases of tubular adenoma with mild dysplasia, and six with moderate dysplasia. In most cases examined, the surface mucous gel layer was not identified on the adenoma tissues, regardless of the abundance of neoplastic goblet cells (Fig $6 \mathrm{~A}$ and B). A very thin surface mucous gel layer was seen in three cases. In these cases, only the outer layer persisted. 

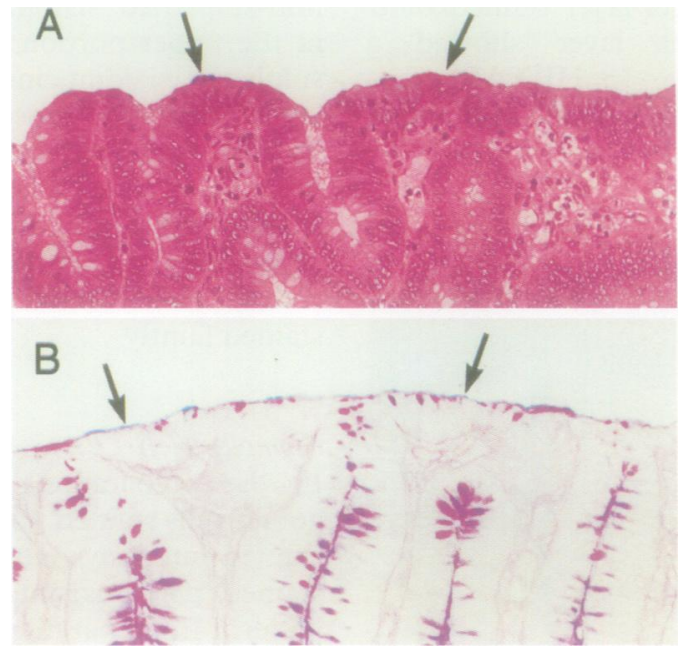

Figure 6: $(A)$ ( $H$ and $E$ ) and $(B)(A B / P A S)$ Adenoma in the transverse colon prepared from serial sections. The surface mucous gel layer is not present on the adenoma tissues, regardless of the abundance of neoplastic goblet cells. Arrows indicate aggregated alcian blue, which was sprayed before fixation. Originally $\times 192$.

\section{Colon cancer}

Hardly any surface mucous gel layer overlaid cancerous tissues in most lesions, although mucins derived from neoplastic goblet cells occasionally adhered to the surface. Even in the region where numerous goblet cell type carcinoma cells lined the luminal surface, the inner layer was never found (Fig 7A and B).

So called "blue crypts" and the surface mucous gel layer

So called "blue crypts" ${ }^{3}$ were found in four sigmoid colons and one rectum. They occurred singly or included several crypts but could not be differentiated morphologically from ordinary crypts. Goblet cells lining these crypts and lining the mucosal surface characteristically stained blue/purple with AB/PAS (Fig $8 \mathrm{~A})$ but stained more intensely with HID/AB
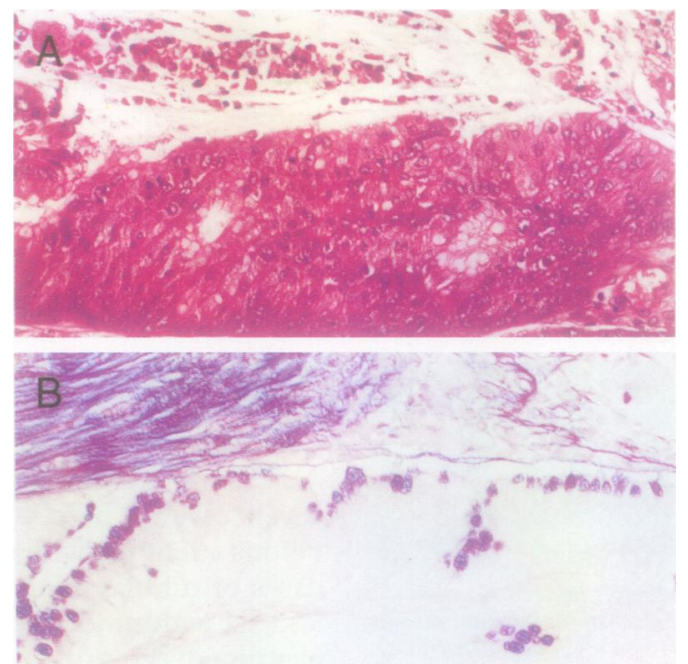

Figure 7: $(A)$ (H and $E)$ and $(B)$ ( $A B / P A S)$ Cancer of transverse colon prepared from serial sections. Although mucins derived from neoplastic goblet cells occasionally adhere to the surface, the inner layer is absent, even where numerous goblet cell type carcinoma cells line the luminal surface. Originally $\times 192$ than those of the surrounding mucosa (Fig 8B). The goblet cells were unstained by PA/SB/ $\mathrm{KOH} / \mathrm{PAS}$ (Fig 8C) but stained blue with PA/ TS/KOH/PAS (Fig 8D). The inner layer also stained similarly as long as goblet cells lining the mucosal surface exhibited similar properties (Fig 8A, B, C, and D). In the more peripheral region, similar mucins were spread along the boundary layer between the inner and outer layers (Fig 9A and B). Thin layers of similar mucins were occasionally seen in the outer layer.

\section{Effect of alkaline hydrolysis on AB/PAS and $H I D / A B$ staining}

Prior alkaline hydrolysis with potassium hydroxide greatly enhanced PAS reactivity of most goblet cells throughout the colon. A similar effect was confirmed for their alcianophilia. This pretreatment also enhanced HID reactivity of mucins. The surface mucous gel layer also gained higher reactivities for these stains. The effect of this pretreatment was most evident in the sigmoid colon, although the surface mucous gel layer still stained less than that of the rectum with $\mathrm{HID} / \mathrm{AB}$ stain. After this pretreatment, goblet cells and the surface mucous gel layer remained unstained with PA SB/KOH/PAS and stained homogeneously blue with PA/TS/KOH/PAS. The "blue crypts" and their mucins secreted, on the other hand, were not influenced by this pretreatment and therefore became indistinguishable from the surrounding crypts.

In the four cases examined by frozen sections, the surface mucous gel layer appeared as a continuous layer coating the mucosal surface and consisted of an inner and an outer layer (Fig 10A, B, and C). The inner layer clearly showed a vertical striped pattern which reflected the mucus spouting from each goblet cell. The outer layer showed no particular pattern, and its luminal surface was not clear. The thickness of the inner layer was $19.6(3.0)$ $\mu \mathrm{m}$ (range 17.3-23 $\mu \mathrm{m}$ ) (Fig 10A, B, and C). In the inner layer, bacteria were seen along the vertical stripes (Fig 10A and B).

\section{Discussion}

The present study showed that fixation in Carnoy's solution preserves the surface mucous gel layer in ordinary paraffin sections and allows these to be analysed by histochemical techniques.

Several attempts have been made to observe the surface mucous gel layer of the gastrointestinal tract. ${ }^{4-15}$ Kerss et al explored it by preparing unfixed thin sections of rat, frog, and human stomach ${ }^{7}$ and recently Pullan et al prepared sections of human colon and measured its thickness. ${ }^{16}$ They also used Carnoy's fixation to support the existence of the surface mucous gel layer of the colon. As stated previously, sectioning of the surface mucous gel layer by razor blades is not easy because of its stickiness. ${ }^{1}$ In addition, histochemical analysis of this layer is difficult as it dissolves in solution during staining. Ota and 
Katsuyama showed that Carnoy's solution was a useful fixative to preserve the mucus in paraffin blocks. ${ }^{1}$ The surface mucous gel layer was histochemically analysed by preparing thin sections, although there was obvious shrinkage of the mucus during fixation and preparation of paraffin wax blocks. ${ }^{12}$

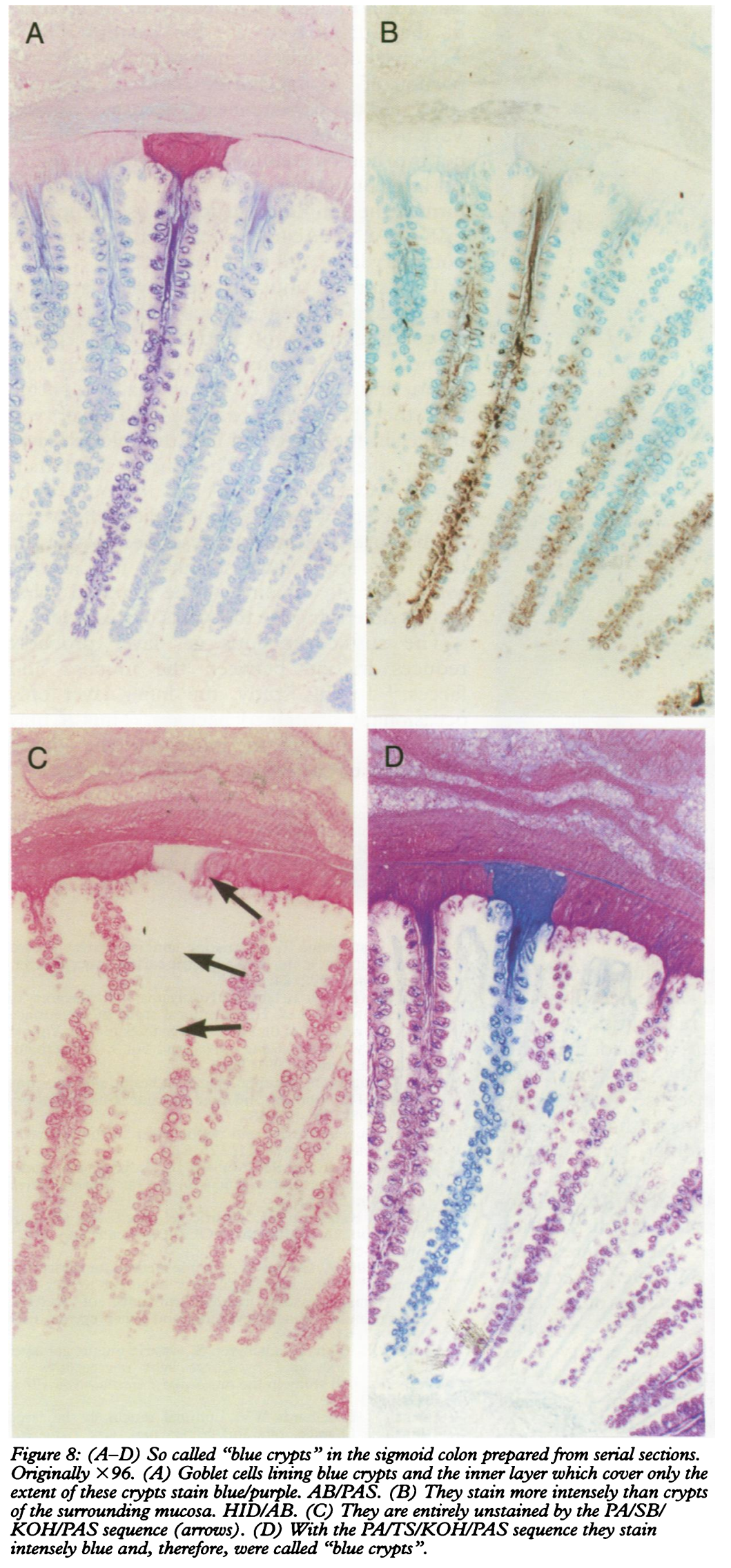

The present study confirmed two layers in the surface mucous gel, the inner layer and the outer layer, as suggested previously. ${ }^{2}$ This structure was consistent in all cases examined but the question still remained whether the structure was an artificial one or not. Several findings, however, indicate the presence of this pattern. Firstly, the inner and outer layers were clearly identified in frozen sections, although the inner frozen layers were thicker than they were in paraffin sections. The luminal surface of the outer layers was not very clear in the frozen sections but was obvious in the paraffin sections. Secondly, size, distribution, and mucin content of goblet cells in the tissue preparations fixed in Carnoy's solution did not differ significantly from these features of goblet cells fixed in ordinary formalin. This finding indicates that abrupt mucin discharge did not occur during fixation in Carnoy's solution. Thirdly, the inner layer was consistently absent on adenoma or carcinoma tissues which contained numerous goblet cell type neoplastic cells. Fourthly, the surface coat, which characterises the apical surface of covering epithelium including goblet cells, preserved well under the inner layer, suggesting no disruption of the apical plasma membrane. Fifthly, the inner layer was not found in ileum, which is also rich in goblet cells. Other support comes from our study on the human stomach. Gastric mucosa often showed intestinal mucosa which contained plenty of well developed goblet cells. In the stomach, however, we have never found the inner layer in the surface mucous gel layer.

So called "blue crypts" provided the clue to explore the origin of mucins in the surface mucous gel layer. The term "blue crypt" was coined by Kato et al because of the characteristic reaction to PATS/ $/ \mathrm{KOH} /$ PAS. $^{3}{ }^{1718}$ Its relevance as a precancerous lesion was contradicted by recent study, ${ }^{18}$ however. The present study showed that goblet cells lining blue crypts lacked $8-\mathrm{O}-\mathrm{AcNeuAc}$, a histochemical marker of the large intestine, as goblet cell mucins remained negative by $\mathrm{PA} /$
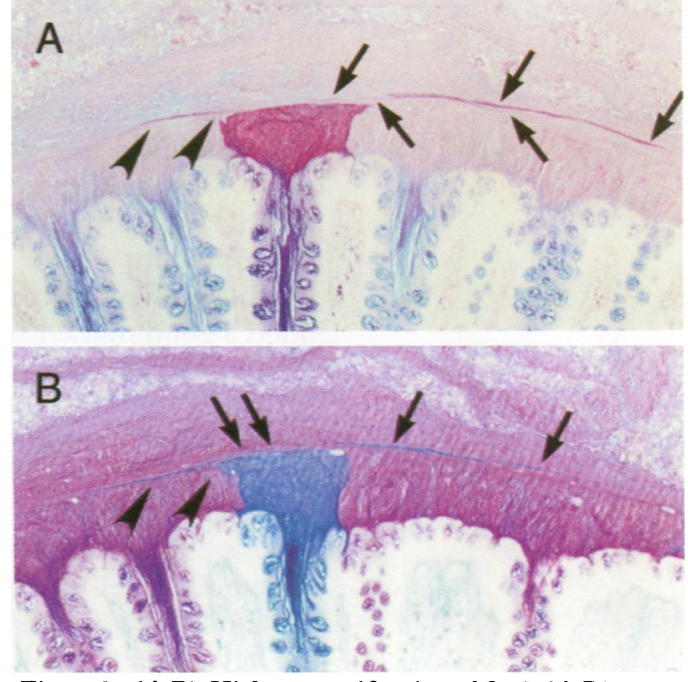

Figure 9: $(A, B)$ Higher magnification of fig $8(A, D)$. Evidence that mucus derived from "blue crypts" spreads along the boundary layer between the inner and outer layers (arrow heads) or spreads into the outer layer (arrows). Originally $\times 192$ 


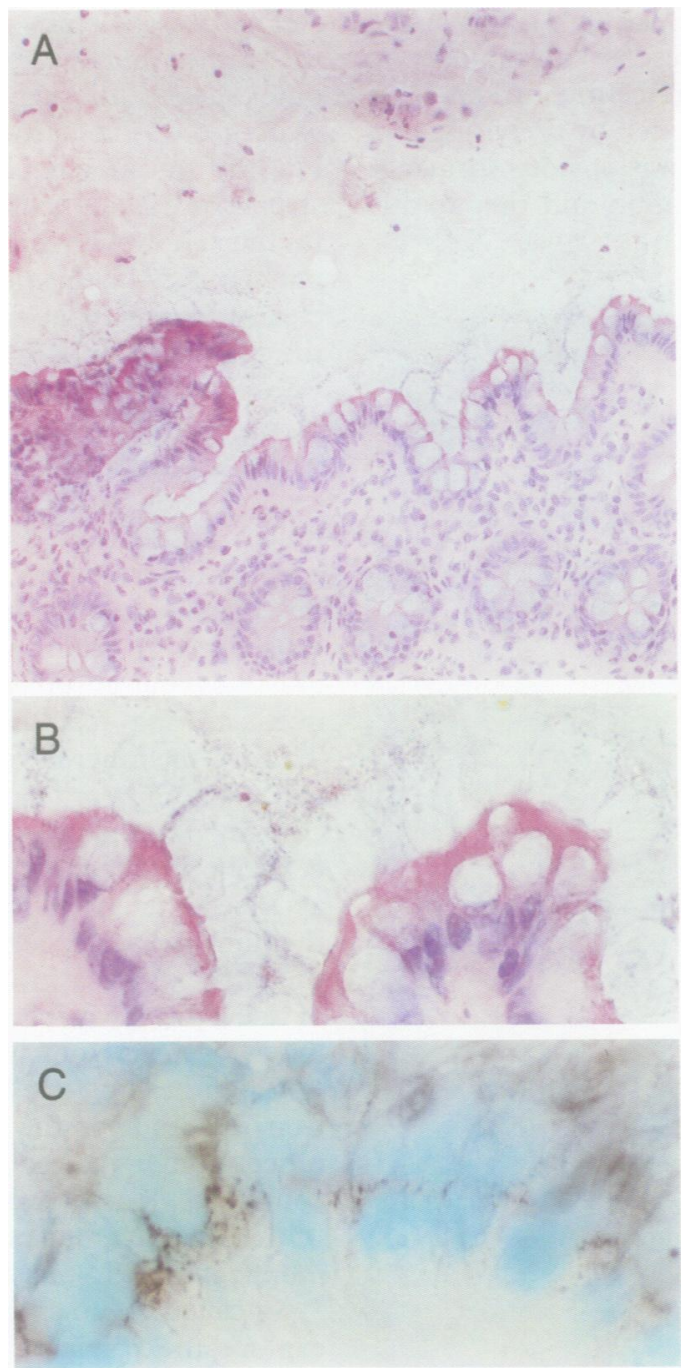

Figure 10: (A-C) Prepared from frozen sections. (A) The mucosal surface is coated by the surface mucous gel layer consisting of two layers. Haematoxylin and eosin. Ascending colon. Originally $\times 192$. (B) At higher magnification, the vertical striped pattern of the inner layer is evident. Bacteria are seen along the vertical stripes. Originally $\times 613$. (C) The inner and outer layers are also evident. HID/AB. Originally $\times 766$.

SB/KOH/PAS and stained blue by PATS/ $\mathrm{KOH} / \mathrm{PAS}$ and previous alkaline hydrolysis did not alter histochemical reactivities. Mucins derived from "blue crypts" formed the inner layer which covered only the extent of 8-O-AcNeuAc free goblet cells. These results clearly indicated that mucins in the inner layer are derived from the goblet cells directly underlying it.

Mucins free from 8-O-AcNeuAc ${ }^{17-20}$ provided a good marker to explore the distribution of mucins in the outer layer where these mucins spread, forming a thin layer. The multilaminated structure found in the outer layer most possibly reflects different physicochemical properties of the different types of mucins $^{20}{ }^{21}$ secreted simultaneously from the same goblet cell or separately from the goblet cells lining the different levels of the crypts.

The effect of alkaline hydrolysis was found not only in the stains related to 8-O-AcNeuAc but also in stains for acid groups, HID and AB. The alkaline hydrolysis used in this study was relatively mild, and is known to cleave $\mathrm{O}$-acyl groups on C-7,8, and 9 of sialic acid. In addition it might also cleave the ester linkage between acid groups and hydroxyl groups of sugar moieties, resulting in increased HID and $A B$ reactivities of acid mucins.

Histochemical staining suggested that the mucins in the outer layer stained similarly to goblet cell mucins. They also suggested that at least sugar moieties of mucins were maintained in the outer layer, as, for example, 8-OAcNeuAc occupies the non-reducing terminal portion of oligosaccharides, and its existence suggested the persistence of saccharide chains. Various mucins derived from goblet cells did not mix homogeneously in the surface mucous gel layer but rather stacked on each other and formed the laminated structure, as exemplified by $8-\mathrm{O}-\mathrm{AcNeuAc}$ free mucins spread along the boundary layer and in the outer layer.

The surface mucous gel layer varied in thickness in different regions of the colon. The descending order of thickness was rectum, sigmoid colon, transverse colon, ascending colon, and caecum. Pullan et al also reported that the the surface mucous gel layer was thicker in the left colon and the thickest layer was in the rectum. ${ }^{16}$ The thickness in their report was about twice that of ours. The difference between the two studies reflects the method used, because, as described previously, there was appreciable shrinkage in Carnoy's solution. ${ }^{12}$ It remains to be clarified what factors determine the thickness of this layer.

The surface mucous gel layer probably reduces friction between the mucosa and faeces. $^{21}$ In this study, the inner layer only occasionally contained bacteria. Thus it may also play a part in inhibiting the direct adherence of bacteria to colonic epithelia. ${ }^{22} 23$

We express appreciation to Professor Kendo Kiyosawa and Emeritus Professor Seiichi Furuta for their advice and encouragement; and Drs Jun Nakayama, Keiko Ishii, Ikuo Matsuyama, Masayoshi Hayama, and Osamu Yamagami for technical assistance.

1 Ota $\mathrm{H}$, Katsuyama T. Alternating laminated array of two types of mucin in the human gastric surface mucous layer. Histochem $\mathcal{F}$ 1992; 24: 86-92.

2 Akamatsu T, Ota T, Ishii $\mathrm{K}$, Nakayama J, Katsuyama T, Matsuzawa $\mathrm{K}$, et al. Histochemical study of the surface mucous gel layer of the human large intestine. In: Yunoki $\mathrm{K}$, ed Cytoprotection and cytobiology. Vol 9. Amsterdam: K, ed Cytoprotection and cytobiolo

3 Kato Y, Sugano H. Morphological studies on precancerous lesions of the stomach and large intestine. Gan To Kagaku Ryoho 1983; 10: 443-58.

4 Iida F. Mucous barrier and peptic ulcer of the stomach. Gastroenterol fpn 1976; 11: 175-81.

5 Morris GP, Harding RK, Wallace JL. A functional model for extracellular gastric mucus in the rat. Virchows Arch 1984; 46: 239-51.

6 Bickel M, Kauffman GL. Gastric gel mucus and effect of distension, 16,16-dimethyl PGE2. Gastroenterology 1981; 80: $770-5$.

7 Kerss S, Allen A, Garner A. A simple method for measuring thickness of the mucus gel layer adherent to rat, frog and human gastric mucosa: influence of feeding, and human gastric mucosa: influence of feeding, prostaglandin, N-acety

8 Sandzen B, Blom H, Dahlgren S. Gastric mucus gel layer thickness measured by direct light microscopy. An thickness measured by direct light microscopy. An 23: $1160-4$.

9 Sakata T, Engelhardt WV. Luminal mucin in the large intestine of mice, rats and guinea pigs. Cell Tissue Res 1981; 219: 629-35.

10 Rozee KR, Cooper D, Lam K, Costerton JW. Microbial flora of the mouse ileum mucous layer and epithelial surface. Appl Environ Microbiol 1982; 43: 1451-63.

11 Bollard JE, Vanderwee MA, Smith GW, Tasman-Jones C, Gavin JB, Lee S. Preservation of mucus in situ in rat colon. Dig Dis Sci 1986; 31: 1338-44. 
12 Szentkuti L, Eggers A. Stabilization of pre-epithelial mucus gel in cryostat sections from rat colon with celloidin. Stain gel in cryostat sections from rat
Technology 1990; 65: 179-81.

13 Szentkuti L, Riedesel H, Enss ML, Gaertner K, Von Engelhardt W. Pre-epithelial mucus layer in the colon on conventional and germ-free rats. Histochem $\mathcal{F} 1990 ; 22$ : 491-7.

14 Garland CD, Nash GV, McMeekin TA. The preservation of mucous and surface-associated microorganisms using acrolein vapour fixation. $\mathcal{F}$ Microsc 1982; 128: 307-12.

15 Tock EP, Pearse AGE. Preservation of tissue mucins by freeze-drying and vapour fixation. I. Light microscopy. fournal of the Royal Microscopical Society 1965; 84: 519-637.

16 Pullan RD, Thomas GAO, Rhodes M, Newcombe RG, Williams GT, Allen A, et al. Thickness of adherent mucus
gel on colonic mucosa in humans and its relevance to gel on colonic mucosa in hum
colitis. Gut 1994; 35: 353-9.

17 Muto T, Kamiya J, Sawada T, Agawa S, Morioka Y, Utsunomiya J. Mucin abnormality of colonic mucosa in patients with familial polyposis coli. Dis Colon Rectum 1985; 28: 147-8

18 Sugihara K, Jass JR. Colorectal goblet cell sialomucin heterogeneity: its relation to malignant disease. $f$ Clin Pathol 1986; 39: 1088-95.

19 Fuller CE, Davies RP, Williams GT, Williams ED. Crypt restricted heterogeneity of goblet cell mucus glycoprotein in histologically normal human colonic mucosa: a potential marker of somatic mutation. Br f Cancer 1990; potential $382-4$
20 Jass JR, Roberton AM. Colorectal mucin histochemistry in health and disease: a critical review. Pathol Int 1994; 44: health and

21 Smith B, Butler M. The autonomic control of colonic mucin secretion in the mouse. Br F Exp Pathol 1974; 55: 615-21.

22 Specian RD, Oliver MG. Functional biology of intestinal goblet cells. Am f Physiol 1991; 260: C183-93.

23 Piotrowski J, Slomiany A, Murty VLN, Fekete Z, Slomiany $\mathrm{BL}$. Inhibition of Helicobacter pylori colonization by sulfated gastric mucin. Biochem Int 1991; 24: 749-56.

24 Spicer SS. Diamine methods for differentiating mucopolysaccharides histochemically. $\mathcal{F}$ Histochem Cytochem polysaccharides hist

25 Culling CFA, Reid PE, Clay MG, Dunn WL. The histochemical demonstration of O-Acylated sialic acids in
gastrointestinal mucins. Their association with the potassium hydroxide-periodic acid-Schiff effect. $\mathcal{F}$ Histochem Cytochem 1974; 22: 826-31.

26 Katsuyama T, Ono K, Nakayama J, Kanai M. Recent advances in mucosubstance histochemistry. In: Kawai K, ed. Gastric mucus and mucus secreting cells. Amsterdam: Excerpta Medica, 1985: 1-18.

27 Culling CFA, Reid PE, Dunn WL. A new histochemial method for the identification and visualization of both side chain acylated and non-acylated sialic acids. $f$ Histochem Cytochem 1976; 24: 1225-30.

28 Hayama $M$, Ono $K$, Katsuyama T. An improved method for identifying 8-O-acetyl-N-acetylneuraminic acid. Stain Technology 1985; 60: 201-5. 